in endocytosis, and it is consistent with coordinated regulation of post-translational modification of synaptojanin 1 to achieve integration of membrane retrieval at axon terminals. This opens a door to future understanding of signaldirected endosomal plasticity, which could be based on the established knowledge of clathrinmediated endocytosis.
1. Palmer, A. \& Klein, R. Genes Dev. 17, 1429-1450 (2003).

2. Irie, F., Okuno, M., Pasquale, E. B. \& Yamaguchi, Y. Nature Cell. Biol. 7, 501-509 (2005).

3. Sorkin, A. Curr. Opin. Biol. 16, 392-399 (2004).

4. Heuser, J.E. \& Reese, T.S. J. Cell Biol. 57, 315-344 (1973).

5. Sahin, S. \& Bibb, A. Proc. Natl Acad. Sci. 101, 1112 1113 (2004).

6. Slepnev, V. I. \& De Camilli, P. Nature Rev. Neurosci. 1, 161-172 (2000).
7. Song, W. \& Zinsmaier, K.E. Neuron 40, 665-670 (2003).

8. McPherson, P.S. et al. Nature 379, 353-357 (1996).

9. Barry, M. F. \& Ziff, E. B. Curr. Opin. Neurobiol. 12, 279-286 (2002).

10. Collingridge, G. L., Isaac, J. T. \& Wang, Y.T. Nature Rev. Neurosci. 5, 952-962 (2004).

11. Lee, S.H., Simonetta, A. \& Sheng, M. Neuron 43, 221-236 (2004).

\title{
Dpp gets in shape
}

In the 18 March issue of Science (307, 1785 and 1789; 2005), two groups have taken a fresh look at what the BMP-like factor Decapentaplegic (Dpp) does in the Drosophila melanogaster wing. They find that its primary function is not in promoting cell survival, but in ensuring the correct architecture of epithelial cells.

Epithelial cells come in all shapes and sizes, and we don't know that much about what determines the outcome in each case. At Harvard, Matt Gibson and Nobert Perrimon set out to identify proteins that are important for these decisions during Drosophila imaginal disc development. Using the FLP/FRT mosaic clone system to disrupt genes in small groups of wing disc cells, they found a mutant that showed a particularly unusual phenotype: the epithelium lost its normal columnar organization and the mutant cells retracted from the apical surface to form cysts. They were surprised to find that the culprit responsible for this was the transforming growth factor $\beta$ (TGF- $\beta$ ) type I receptor, because the ligand for this receptor, Dpp, has previously been linked to cell survival in the wing. Nonetheless, they were able to confirm the extrusion phenotype and show that although more cells do die as a secondary effect when the Dpp pathway is disrupted, many of the cysts remain viable. Thus, the primary defect seems to occur in epithelial morphogenesis.

Jie Shen and Christian Dahmann in Dresden came to similar conclusions by comparing what happens when Dpp and/or Jnk-mediated apoptotic signalling is removed from clones of wing cells. The extent of the defects that they saw upon Dpp loss indicated that it must be doing something more than simply preventing apoptosis. Similarly to the first study, they also saw that cells that lacked Dpp had lost their normal apical-basal morphology and were extruded from the epithelial surface.

How does Dpp normally keep cells in their proper place? The two groups went on to find that Dpp signalling activity forms a medialto-lateral gradient in the epithelium, which correlates with the columnar shape of cells and a gradient of apically enriched microtubules.

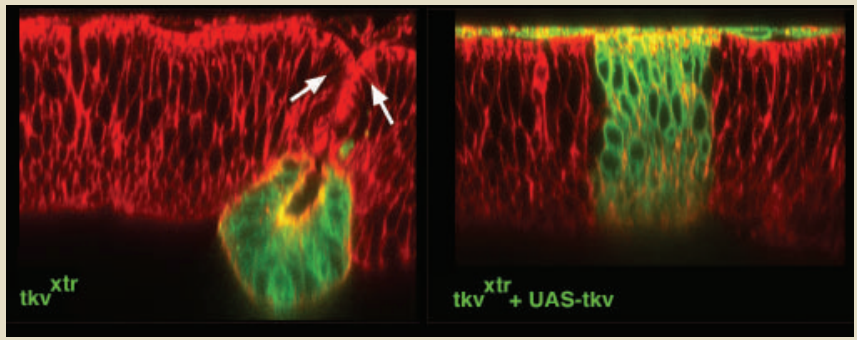

Dpp signalling is important for epithelial architecture. Left: a GFPexpressing mutant clone that lacks the Dpp/BMP receptor Thickveins (Tkv) extrudes from the cell layer as an inverted cyst. Right: a mutant clone is rescued from extrusion by expression of an exogenous Tkv receptor construct. Image kindly provided by Matt Gibson, Harvard Medical School, and reproduced from Gibson \& Perrimon (Science 307,$1785 ; 2005$ ) with permission from the American Academy of Sciences (C) (2005).

This microtubule polarity is disrupted when Dpp signalling is lost. So it seems that Dpp acts in a position-specific manner to determine epithelial cytoskeletal architecture. What we need to know now is how it controls morphogenesis and whether its direct targets include cytoskeletal or adhesion factors.

These studies reveal a function for Dpp more akin to its role in other morphogenetic processes such as dorsal closure, suggesting that its mechanism of action may be similar in each case. As Gibson and Perrimon discuss, it is also tempting to speculate that this may reflect a conserved function of BMP signalling pathways in human epithelia. Two components of this pathway - a type I BMP receptor and SMAD4 - have been implicated in the genetic disorder juvenile polyposis, and it is possible that the epithelial polyps formed in the intestine of patients may originate from a common molecular defect.

ALISON SCHULDT 